\title{
Device Characterization and Modeling for the Design of UHF Class-E Inverters and Synchronous Rectifiers
}

\author{
L. Rizo, M.N. Ruiz and J. A. García. \\ Dept. Communications Engineering \\ University of Cantabria, UC \\ Santander, Spain \\ joseangel.garcia@unican.es
}

\begin{abstract}
In this paper, the advantages derived from an appropriate characterization and modeling of active and passive devices, leading to the optimized design of Ultra-High Frequency (UHF) Class-E inverters and synchronous rectifiers, are highlighted. While the combination of a couple of low-frequency and RF measurement techniques is shown to be valid for the extraction of a simplified model as a switch, a more complex approach may be required if also addressing the design of the continuous wave $(\mathrm{CW})$ driving network or if interested in taking fully advantage of other transistor characteristics. Design examples, based on GaN HEMTs and a GaAs E-pHEMT, are presented, in which the parasitics of the employed coils and capacitors are also taken into consideration. Wireless transmitting and powering applications have been addressed.
\end{abstract}

Keywords-Class E, DC-DC converter, E-pHEMT, frequency modulation, GaN HEMT, inverter, outphasing, synchronous rectifier, $\boldsymbol{U H F}$.

\section{INTRODUCTION}

During the last years, the Radiofrequency (RF) and Microwave engineering community has shown an increased interest in the design of class-E power amplifiers. The critical requirement for transmitting modern wireless communication standards (LTE, WiMAX, etc.) in a highly linear and efficient way [1] has motivated a lot of research activities on $\mathrm{GaN}$ HEMT-based zero voltage switching (ZVS) and zero voltage derivative switching (ZVDS) inverting topologies, optimized for operation under bias or load modulating conditions. In parallel, the need for minimizing losses in the receiving end of far-field wireless power transmission links [2] has led to an increased work in the design of its time reversal dual, the classE rectifier, using not only Schottky diodes, but also high performance transistor technologies. The integration of both parts in resonant converters [3], [4] is, at the same time, under strong consideration by Power Electronics (PE) specialists, motivated by the implementation of high performance (fast response and small footprint) DC/DC converters [5].

In a growing imbrication scenario of PE and RF areas, this paper addresses the relevance of device characterization and modeling techniques in the RF implementation of well-known $\mathrm{PE}$ topologies. The design of an outphasing GaN-based inverter, operating at $770 \mathrm{MHz}$, a $900 \mathrm{MHz}$ self-synchronous
E-pHEMT rectifier and a frequency-controlled $1 \mathrm{GHz}$ class $\mathrm{E}^{2}$ resonant converter will be under consideration.

\section{ACTIVE DEVICE CHARACTERIZATION AND MODELING}

When extracting a simplified switch model $\left(R_{\text {on }}, C_{\text {out }}\right.$ and $R_{\text {off }}$ ) for a III-V compound transistor (the case of GaAs or GaN HEMT technologies), low-frequency dispersion effects should be taken into account. Being not only related to self-heating, but also to trap states, they could lead to errors in the estimation of the ON-state resistance if derived from the slope of the DC curves. Launching narrow pulses (hundreds of ns or a few $\mu \mathrm{s}$ ) from the selected OFF-state biasing point $\left(V_{G S}=-3.4\right.$ $\mathrm{V}$ and $V_{D S}=28 \mathrm{~V}$ for the case of the CGH60030D die from Cree Inc. in Fig. 1a), with a duty cycle below $1 \%$, the dynamic $R_{o n}$ may be properly estimated.

a)

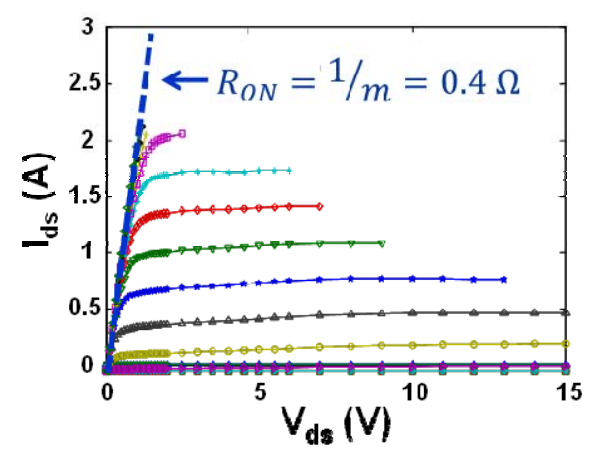

b)

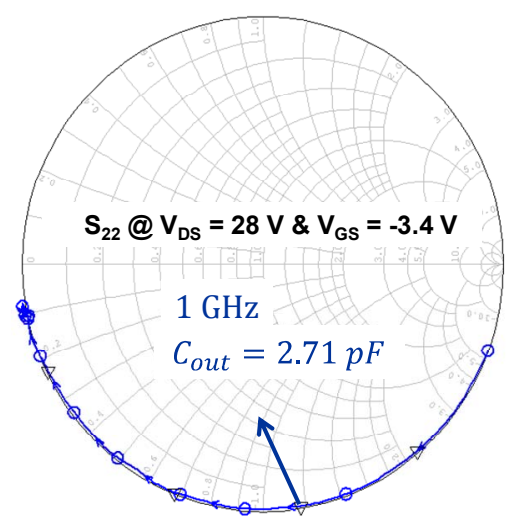

Fig. 1 Extraction of a) $R_{o n}$, from pulsed I/V measurements, as well as of b) $C_{o u t}$ and $R_{\text {off }}$, from [S] parameters. The results correspond to a CGH60030D GaN HEMT die from Cree Inc. 
The output equivalent capacitance and OFF-state resistance may be obtained, instead, from the device $S_{22}$ parameter, measured at the same biasing point with the aid of a vector network analyzer (see Fig. 1b).

While this simple switch representation may be good enough for synthesizing a class $\mathrm{E}$ drain terminating network [6], the design of the $\mathrm{CW}$ gate driving circuit or the operation of the device in a self-synchronous rectifying mode would require from additional parameters or elements (the case of those describing the gate-to-channel Schottky junction). In Fig. $2 \mathrm{a}$, a more elaborated nonlinear model of this kind is presented, in this case for a VMMK-1218 GaAs E-pHEMT from Avago Technologies. Aimed for its use in the design of a synchronous rectifier for far-field wireless powering applications, attention should be paid to the reproduction of the third quadrant of the device I/V characteristics, not a common feature in most available models for RF and microwave transistors, usually conceived to provide a good fit of the device saturated region, where current source mode amplifying classes (A, AB, B and C) usually operate.

In the proposed equation for the $I_{d s}\left(V_{g s}, V_{g d}\right)$ main nonlinearity [7], continuous and continuously derivable functions have been included for accurately describing the exponential nature of the sub-threshold device behavior. A comparison of measured and predicted current values is presented in Fig. 2b [7].

a)

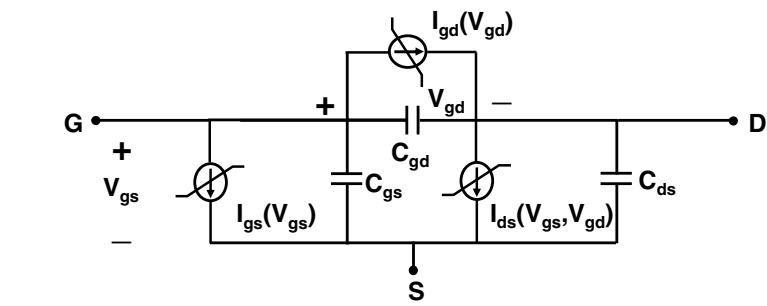

$$
\begin{gathered}
I d s\left(V_{g s}, V_{g d}\right)= \\
=\beta\left[1+\lambda\left(V_{g s}-V_{g d}\right)\right]\left\{\left[\alpha\left(V_{g s}-V_{t h}\right)+\ln \left(2 \cosh \left(\alpha\left(V_{g s}-V_{t h}\right)\right)\right)\right]\left(1+\mu V_{g s}\right)\right. \\
\left.-\left[\alpha\left(V_{g d}-V_{t h}\right)+\ln \left(2 \cosh \left(\alpha\left(V_{g d}-V_{t h}\right)\right)\right)\right]\left(1+\mu V_{g d}\right)\right\}
\end{gathered}
$$

b)

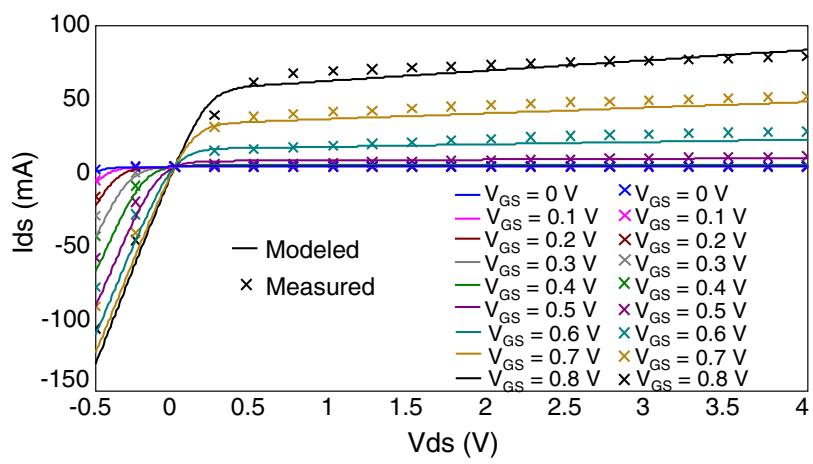

Fig. 2 a) Nonlinear equivalent circuit model together with its b) I/V prediction capability for the VMMK-1218 E-pHEMT from Avago Tech.

Widely accepted models in the industry for RF/microwave GaN HEMT devices, usually based in the equation proposed by Fager [8], may be also conveniently modified for improved reproduction of the linear region and the inverse operation.
Taking advantage of the equations in [9], [10], addressing by that time the nonlinear distortion prediction of FET devices operated as resistive switches, attenuators or mixers, the gate to source and gate to drain voltages may be used for describing the real device symmetry.

\section{UHF CLASS-E TOPOLOGIES}

At UHF frequencies, high Q coils and capacitors represent the best choice for the design of the passive networks. While in the classical topology [6], a simple series LC circuit may force a sinusoidal current through the load while also providing the desired inductive termination at the fundamental, coil parasitics may have a detrimental influence at these frequency bands. Considering the tremendous impact of the second and third harmonics over the efficiency figure [11], two topologies may be preferred among others: a multi-resonant or poly-harmonic terminating network [12] and an LC network based on an appropriate high Q coil, self-resonating between those two frequency components [13]. The latter, represented in Fig. 3, may be a good selection for approximating the desired class $\mathrm{E}$ conditions with a compact and low footprint implementation.

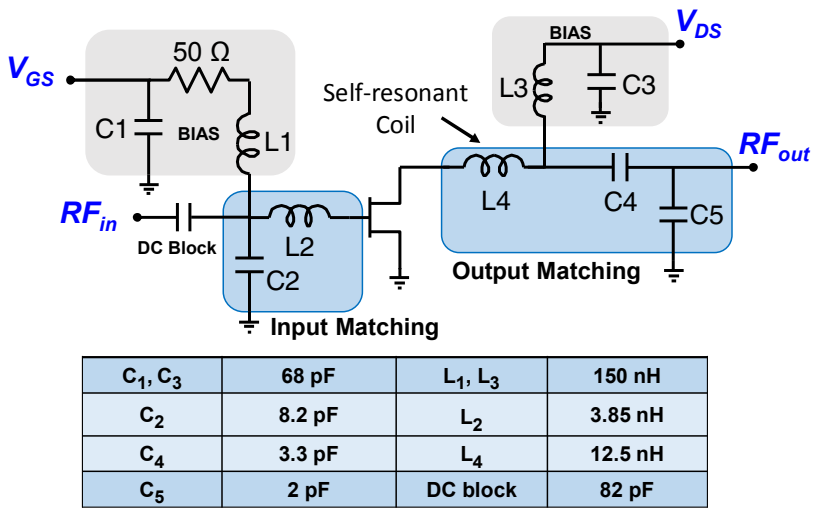

Fig. 3 Class-E lumped-element topology based on a self-resonant high Q coil.

The values in the included table are for a $770 \mathrm{MHz}$ design, using the packaged CGH35030F GaN HEMT device from Cree Inc. (the package contains the CGH60030D die, whose characterization results were presented in Fig. 1).

The capacitor in series, $C_{4}$, would allow a fine adjustment of the desired inductive reactance at the switching frequency, $0.2116 /\left(\omega C_{\text {out }}\right)$, while the capacitor to ground, $C_{5}$, would help transforming the reference impedance at $\mathrm{RF} /$ microwave bands $(50 \Omega)$ to the optimum or nominal drain resistive load $0.1836 /\left(\omega C_{\text {out }}\right)[6]$.

Although representing an inverter, the lumped element topology in Fig. 3 could also work in its time-reversed mode: a class E rectifier [14]. Depending on the application, the required gate driving signal may be independent of (although properly synchronized) or derived from the AC signal, in the UHF band, to be rectified. A precise control could be obtained in the first case, while a simpler implementation from the latter.

If finally cascading two of these topologies, a double class $\mathrm{E}$ resonant $\mathrm{DC} / \mathrm{DC}$ converter would result [15]. Its schematic and values, in this case corresponding to a $1 \mathrm{GHz}$ design using the CGH60030D die device, are included in Fig. 4. 
Two capacitors, $C_{s}$, are employed in the interconnecting network as to provide a fine tuning of the series resonant circuit below the fundamental, while also avoiding undesired asymmetries in the device terminations due to the impedance transformation effects of the required lengths of transmission lines between them.

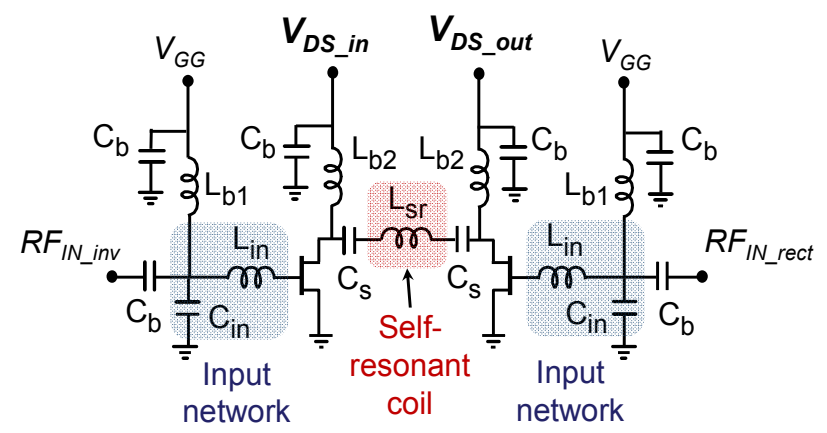

\begin{tabular}{|c|c|c|c|}
\hline $\mathrm{C}_{\text {in }}$ & $6.8 \mathrm{pF}$ & $\mathrm{L}_{\mathrm{sr}}$ & $8 \mathrm{nH}$ \\
\hline $\mathrm{C}_{\mathrm{s}}$ & $8.2 \mathrm{pF}$ & $\mathrm{L}_{\mathrm{b} 1}$ & $120 \mathrm{nH}$ \\
\hline $\mathrm{C}_{\mathrm{b}}$ & $47 \mathrm{pF}$ & $\mathrm{L}_{\mathrm{b} 2}$ & $18.5 \mathrm{nH}$ \\
\hline \multicolumn{2}{r}{} & Tx. Line $\left(\mathrm{L}_{\text {in }}\right)$ & $30.2^{\circ}$ \\
\cline { 3 - 4 }
\end{tabular}

Fig. 4 Double class $E$ or class $E^{2}$ resonant converter: schematic and values for a $1 \mathrm{GHz}$ design.

\section{UHF IMPLEMENTATION EXAMPLES AND RESULTS}

Implementation examples of class $\mathrm{E}$ topologies at UHF frequencies will be presented in this section, based on the above considered GaN HEMT and GaAs E-pHEMT devices. They include an inverter, a self-synchronous rectifier, and a resonant $\mathrm{DC} / \mathrm{DC}$ converter, conceived for their use in wireless communication or powering applications.

\section{A. Outphasing Inverter}

In Fig. 5a, a photograph with details of an outphasing amplifier [16] (a phase-controlled resonant inverter), operating at $770 \mathrm{MHz}$, is presented. Both constituting class-E switching branches follow the topology suggested in Fig. 3. As proposed in [17], appropriate lengths of transmission lines were adjusted between the output of the amplifiers and the inputs of the reactive or Chireix combiner, in order to produce the desired mutual load modulation loci [18].

Measured results for the efficiency evolution versus power back-off (output power relative to the peak, $35 \mathrm{~W}$ ) are also included in Fig. 5b, where it is shown that the efficiency may be kept over $70 \%$ for a significant dynamic range (a power value nearly 10 times below the peak). Aimed for the efficient and linear transmission of modern wireless communication signals, the case of $4 \mathrm{G}$ Long Term Evolution (LTE), with very high values for the peak-to-average power ratio, class-E based outphasing transmitters currently stand as a promising technique [19]. a)

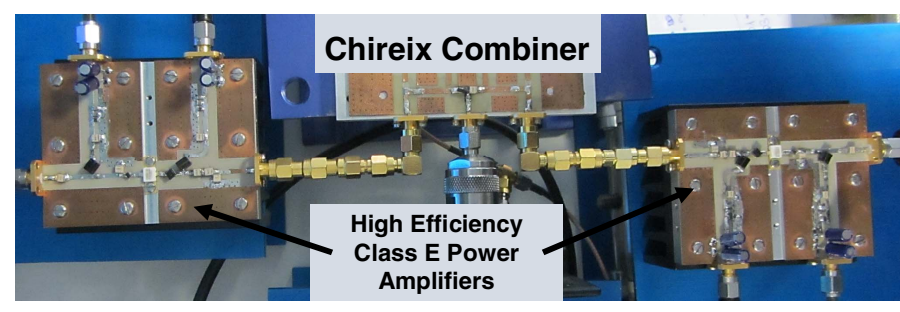

b)

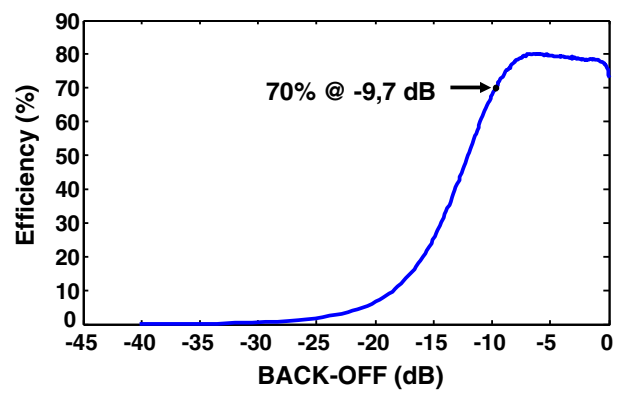

Fig. 5 a) Implementation details of the phase-controlled class-E inverter together with $b$ ) its efficiency vs. output voltage profile.

\section{B. Self-syncrhonous and self-biased rectifier}

A self-synchronous and self-biased E-pHEMT rectifier, also based on a self-resonant drain terminating coil, is shown in Fig. 6. Designed over the VMMK-1218 (model details were presented in Fig. 2), this solution is aimed for its use in farfield $900 \mathrm{MHz}$ wireless powering links. As no additional source would be available for forcing the device operation as a switch, advantage has been taken from the Miller capacitance, $C_{g d}$ [20]. The synthesized impedance at gate terminal was carefully adjusted through simulations to force the required amplitude and phase of the gate driving voltage [7].

a)

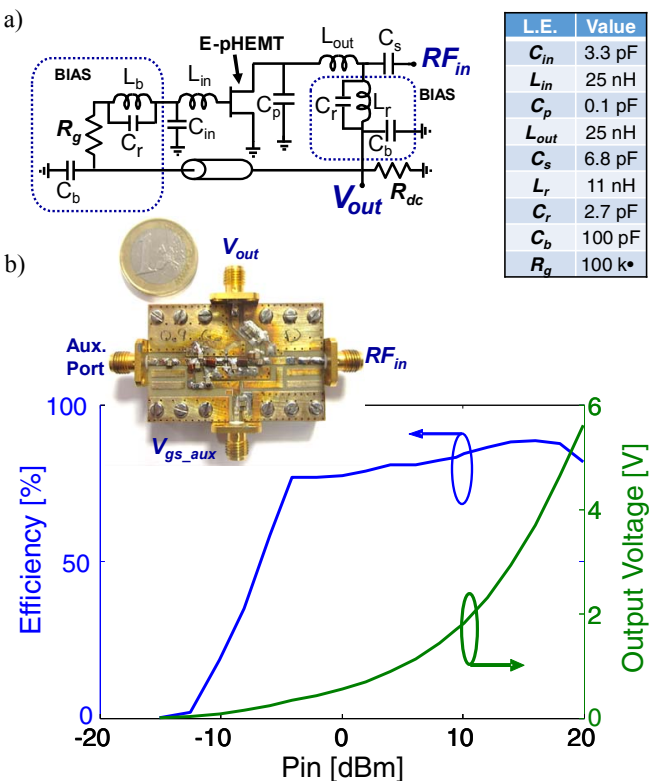

Fig. 6 a) Class-E self-synchronous rectifier based on the VMMK-1218 EpHEMT. b) Evolution of output voltage and efficiency [7]. 
The measured variation of efficiency with the input power level is depicted in Fig. 5b. The gate to source biasing value was also adjusted with the input power level, deriving it from the rectified voltage through the use of a properly calculated resistor, $R_{g}$. Using this adaptive biasing technique, an $88 \%$ efficiency peak was measured at $16 \mathrm{dBm}$, staying over $76 \%$ for power levels above $-4 \mathrm{dBm}$.

\section{FM-controlled Resonant Conveter}

Finally, a photograph of the resonant converter, following the circuit schematic in Fig. 4, is presented in Fig. 7a. Requiring low valued and sized components, the implementation is relatively compact. In Fig. $7 \mathrm{~b}$, the measured output voltage and efficiency profiles are presented in terms of the switching frequency [21]. In the $11 \mathrm{~V}-28 \mathrm{~V}$ range, the voltage follows the frequency in a relatively linear law. Peak drain and overall efficiency values of $80 \%$ and $77 \%$, respectively, have been measured, staying above $70 \%$ for an output voltage $5 \mathrm{~dB}$ below the peak. The power of the driving signals is accounted for in the overall efficiency calculation.

Besides being close to the state-of-the-art for reported high frequency resonant converters, the measured performance may fit the probability density function of modern communication signal envelopes. Taking this feature into account, together with the dynamic response capabilities to be expected from a 1 $\mathrm{GHz}$ frequency of operation, this converter is being evaluated for its use as envelope modulator in envelope tracking or polar transmitters [21].

a)

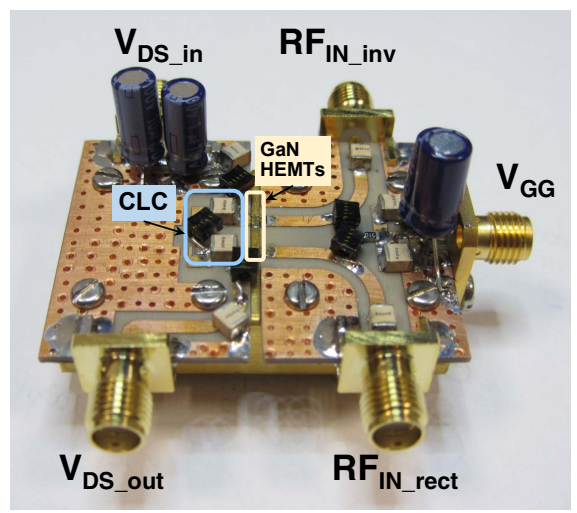

b)

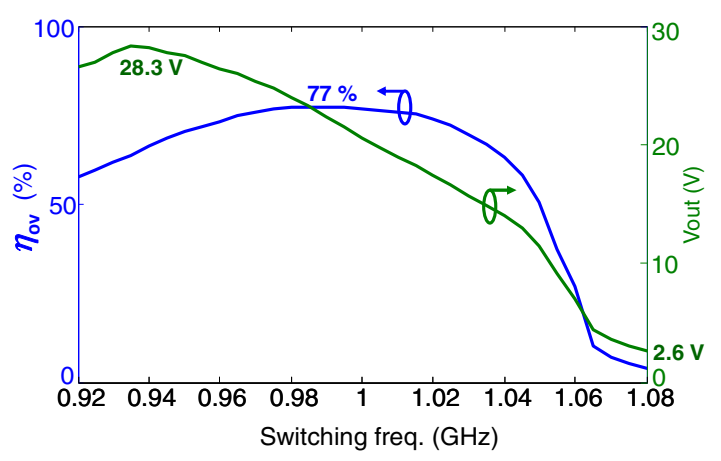

Fig. 7 a) Photograph with details of the $1 \mathrm{GHz}$ class $\mathrm{E}^{2}$ resonant converter. b) Evolution of output voltage and efficiency with the switching frequency.
Using a frequency-modulation, FM, output voltage control as in [15], the converter dynamic performance was characterized. Values for the large signal bandwidth and slew rate of $51 \mathrm{MHz}$ and $1.37 \mathrm{~V} / \mathrm{nS}$, respectively, have been estimated. Along the measured large-signal bandwidth the efficiency kept around $71 \%$. This converter has been also tested with success, handling the envelope of $2 \mathrm{c}-$ and $4 \mathrm{c}-$ WCDMA signals, as in [21].

\section{CONCLUSION}

The combination of appropriate device characterization and modeling techniques is employed in this paper for the optimized design of a GaN HEMT class-E inverter, an EpHEMT class-E synchronous rectifier and a double class $\mathrm{E}$ resonant $\mathrm{DC} / \mathrm{DC}$ converter. Measured results, close to the state-of-the-art for switching frequencies in the UHF band, show the feasibility of these topologies with currently available $\mathrm{RF} /$ microwave device technologies. A lot of work would need to be done in the future for further improving their performance.

a)

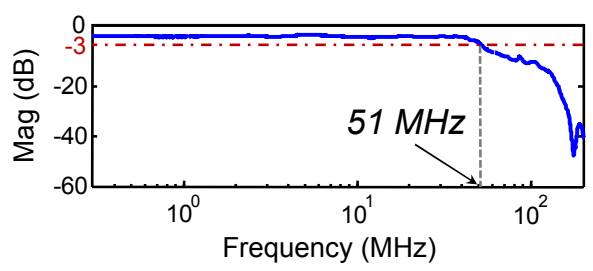

b)

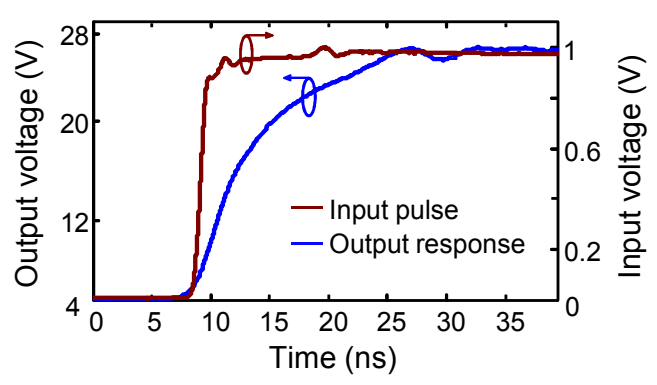

Fig. 8 Characterization of the converter large-signal response: a) bandwidth and $b$ ) slew rate.

\section{ACKNOWLEDGMENT}

This work was supported by the Spanish Ministry MINECO through projects TEC2011-29126-C03-01, co-funded with FEDER, and Consolider CSD2008-00068. The authors wish to thank Mr. Ryan Baker, Cree Inc., and Mr. Creg Ballou, Avago Tech., by their kind assistance, as well as Mrs. Sandra Pana, by the device mounting and bonding. The kind considerations and advice on these and related topics by Prof. Dragan Maksimovic and Prof. Zoya Popovic, Univ. Colorado at Boulder, as well as by Prof. Javier Sebastian, Univ. Oviedo, are highly appreciated. The authors also want to thank Prof. David Perreault, MIT, and Dr. Frederick Raab, Green Mountain Radio Research, by their stimulating words. 


\section{REFERENCES}

[1] F. H. Raab, P. Asbeck, S. Cripps, P. B. Kenington, Z. B. Popovic, N. Pothecary, J. F. Sevic, and N. O. Sokal, "Power Amplifiers and Transmitters for RF and Microwave," IEEE Trans. Microwave Theory Tech., vol. 50, no. 3, pp. 814-826, March 2002.

[2] Z. Popovic, E. A. Falkenstein, D. Costinett, and R. Zane, "Low-Power Far-Field Wireless Powering for Wireless Sensors," Proc. IEEE, vol. 101, no. 6, pp. 1397-1409, June 2013.

[3] R. J. Gutmann, "Application of RF Circuit Design Principles to Distributed Power Converters," IEEE Trans. Ind. Electron. and Control Instrum., vol. IECI-27, no.3, pp. 156-164, Aug. 1980.

[4] J. M. Rivas, O. Leitermann, Y. Han, and D. J. Perreault, "A Very High Frequency DC-DC Converter Based on a Class 2 Resonant Inverter," IEEE Trans. Power Electron., vol. 26, no. 10, pp. 2980-2992, Oct. 2011.

[5] F. Waldron, R. Foley, J. Slowey, A. N. Alderman, B. C. Narveson, S. C. O'Mathuna, "Technology Roadmapping for Power Supply in Package (PSiP) and Power Supply on Chip (PwrSoC)," IEEE Trans. Power Electronics, vol. 28, no. 9, pp. 4137-4145, Sept. 2013.

[6] F. H. Raab, "Idealized operation of the class E tuned power amplifier," IEEE Trans. Circuits and Syst., vol. 24, no. 12, pp. 725- 735, Dec. 1977.

[7] M. N. Ruiz and J. A. García, "An E-pHEMT Self-biased and Selfsynchronous Class E Rectifier," IEEE MTT-S Int. Microw. Symp. Dig., June 2014, pp. 1-3.

[8] C. Fager, J. C. Pedro, N. B. Carvalho, and H. Zirath, "Prediction of IMD in LDMOS Transistor Amplifiers Usign a New Large-Signal Model," IEEE Trans. Microwave Theory Tech., vol. 50, no. 12, pp. 2834-2842, Dec. 2012.

[9] K. Yhland, N. Rorsman, M. García, and H. F. Merkel, "A Symmetrical Nonlinear HFET/MESFET Model Suitable for Intermodulation Analysis of Amplifiers and Resistive Mixers," IEEE Trans. Microwave Theory Tech., vol. 48, no. 1, pp. 15-22, Jan. 2000.

[10] J. A. García, J. C. Pedro, M. L. De la Fuente, N. B. Carvalho, A. Mediavilla, and A. Tazón, "Resistive FET Mixer Conversion Loss and IMD Optimization by Selective Drain Bias," IEEE Trans. Microwave Theory Tech., vol. 47, no. 12, pp. 2382-2392, Dec. 1999.

[11] F. H. Raab, "Class-E, Class-C, and Class- F Power Amplifiers Based Upon a Finite Number of Harmonics," IEEE Trans. Microwave Theory Tech., vol. 49, no. 8, pp. 1462-1468, Aug. 2001.
[12] R. Beltrán and F. H. Raab, "Lumped-element Output Networks for High-efficiency Power Amplifiers," IEEE MTT-S Int. Microw. Symp., May 2010, pp. 324-327.

[13] R. Negra and W. Bächtold, "Lumped-Element Load-Network Design for Class-E Power Amplifiers," IEEE Trans. Microwave Theory Tech., vol. 54, no. 6, pp. 2684-2690, June 2006.

[14] M. K. Kazimierczuk, "Analysis of Class E Zero-Voltage-Switching Rectifier," IEEE Trans. Circuits Syst., vol. 37, no. 6, pp. 747-755, June 1990.

[15] M. K. Kazimierczuk, J. Jozwik, "Resonant DC/DC Converter with Class-E Inverter and Class-E Rectifier," IEEE Trans. Ind. Electron., vol. 36, no. 4, pp. 468-478, Nov. 1989.

[16] H. Chireix, "High Power Outphasing Modulation," Proc. IRE, vol. 23, no. 11, pp. 1370-1392, Nov. 1935.

[17] R. Beltran, F. H. Raab and A. Velazquez, "HF Outphasing Transmitter using Class-E Power Amplifiers," IEEE MTT-S Int. Microwave Symp., June 2009, pp. 757-760.

[18] R. Marante, M. N. Ruiz, and J. A. García, "A UHF Outphasing Transmitter based on Class E Power Amplifiers," WS on Int. Nonlinear Microw. Millimetre-Wave Circ., Sept. 2012, pp. 1-3.

[19] D. A. Calvillo-Cortes, M. P. van der Heijden, M. Acar, M. de Langen, R. Wesson, F. van Rijs, and L. C. N. de Vreede, "A Package-Integrated Chireix Outphasing RF Switch-Mode High-Power Amplifier," IEEE Trans. Microwave Theory Tech., vol. 61, no. 10, pp. 3721-3732, Oct. 2013.

[20] M. Roberg, T. Reveyrand, I. Ramos, E. A. Falkenstein and Z. Popovic, "High-Efficiency Harmonically Terminated Diode and Transistor Rectifiers," IEEE Trans. Microwave Theory Tech., vol. 60, no. 12, pp. 4043-4053, Dec. 2012.

[21] J. A. García, R. Marante, M. N. Ruiz, and G. Hernández, "A 1 GHz Frequency-controlled Class $E^{2}$ DC/DC Converter for Efficiently Handling Wideband Signal Envelopes," in IEEE MTT-S Int. Microw. Symp., June 2013, pp. 1-4. 